\title{
Haemodynamic effects of pregnancy in patients with heart failure
}

\author{
S BLAKE, HILARY O'NEILL, D MACDONALD \\ From the National Maternity Hospital, Holles Street, Dublin
}

\begin{abstract}
SUMMARY Four patients, who were maintained on a constant regimen of treatment, developed congestive cardiac failure during pregnancy. They were examined regularly and carefully during the course of pregnancy to assess the progress of their failure. All four demonstrated unequivocal improvement during the third trimester attributable to obstruction of the inferior vena cava restricting venous return to the right side of the heart. This resulted in a fall in venous pressure in the neck and the resulting fall in right ventricular output could be very valuable in patients with left ventricular failure.
\end{abstract}

Cardiac output during pregnancy has been the subject of controversy over many years. There can be no doubt that it increases by as much as 30 to $50 \%$ but the main uncertainty centres around the timing of the ultimate decline towards the non-pregnant level. The available data are not adequate to resolve the controversy unequivocally but it is clear that during the third trimester the progressively enlarging uterus may compress the inferior vena cava, reducing the venous return to the heart and so the cardiac output. As a result, when the cardiac output is measured with the subject supine it gradually declines and at term is approximately at the non-pregnant level whereas if measured with the subject on her side it does not decline, or does so relatively little, until the puerperium. ${ }^{1-3}$

In the management of patients with heart disease during pregnancy the behaviour of the cardiac output is of crucial importance. An increase in venous return to the right ventricle may precipitate pulmonary oedema in a patient with an already raised left atrial pressure. Rational decisions about drug treatment and more particularly about the need for surgery are not possible without knowing whether to expect improvement or deterioration during the final io weeks. On the basis of those studies done in the lateral position, it is frequently stressed that clinical improvement cannot be anticipated in late pregnancy ${ }^{4}$ and treatment should be planned on this basis. Our experience does not agree with this, and in the hope of throwing further light on this problem we present our

Accepted for publication 22 December 1981 findings in a small group of patients who were in cardiac failure during the course of pregnancy.

\section{Subjects}

Between 1976 and 1980 a special study was made of patients with signs of cardiac failure during pregnancy. The degree of failure was assessed solely by clinical examination, and this limitation demanded that certain criteria be fulfilled. Since isolated or dominant left ventricular failure cannot be quantified accurately by clinical means, it was necessary to include only those patients who had progressed to congestive failure with a definite and clearly visible rise in jugular venous pressure. There were nine such patients. One patient with a high jugular venous pressure caused by cor pulmonale was excluded from the study because of varying airways obstruction which caused frequent and irregular changes in pulmonary vascular resistance. A second patient was excluded because of atrial fibrillation with a rapid and variable ventricular response. A third case proved unacceptable because of thrombosis of a prosthetic valve shortly after 30 weeks gestation, giving a sustained rise in jugular venous pressure. Finally, two patients were excluded because their treatment was varied so much that no conclusion could be drawn as to the intrinsic circulatory state. The remaining four patients proved suitable for study. Three were admitted to hospital during the second trimester because of grade III dyspnoea (NYHA classification). At this stage they had pulmonary venous hypertension but their jugular venous pressure was still not above the 
normal range for pregnancy. From the time of admission they were maintained at rest in bed on a constant regimen of antifailure treatment. The fourth patient (case 4, Table), with moderate rise in jugular venous pressure and mild symptoms, was maintained on a constant drug regimen at home under stable conditions of a constant daily routine.

In all four cases, the jugular venous pressure was checked weekly with the patient sitting up in bed at a constant angle of 45 degrees. The venous pressure was taken as the top of the " $v$ " wave of the internal jugular pulsation. It was classified as grade 0 where the venous pressure was so low that no pulsation was visible, grade 1 where the top of the pulsation was in the lower third of the neck, grade 2 where it was in the middle third, and grade 3 where it was in the upper third or higher. Grades 0 and 1 are normal during pregnancy.

Table Fugular venous pressure during pregnancy

\begin{tabular}{llll}
\hline Case & Cardiac disease & \multicolumn{2}{l}{ fugular venous pressure } \\
\cline { 3 - 4 } & & Maximum & At term \\
\hline 1 & $\begin{array}{c}\text { Triple valve } \\
\text { prostheses }\end{array}$ & Grade 3 & Grade 2 \\
2 & $\begin{array}{c}\text { Mitral } \\
\text { prosthesis }\end{array}$ & Grade 3 & Grade 0 \\
3 & $\begin{array}{c}\text { Mitral } \\
\text { prosthesis }\end{array}$ & Grade 2 & Grade 0 \\
4 & $\begin{array}{c}\text { Mitral } \\
\text { prosthesis }\end{array}$ & Grade 2 & Grade 0 \\
\hline
\end{tabular}

\section{Results}

During the early months of pregnancy, all four patients had a normal jugular venous pressure, but between 25 and 30 weeks two reached grade 2 and two grade 3 (see Table). During the last nine to 10 weeks, the pressure declined to normal in three cases and from a high grade 3 (up to the ear-lobes) to a low grade 2 in one case (case 1 in Table). In addition, in one patient a systolic murmur of functional tricuspid regurgitation disappeared at 38 weeks (case 3 in Table). In all patients symptoms improved pari passu with the improvement in signs.

\section{Discussion}

The findings noted here suggest that in practice patients with cardiac failure tend to improve during the final 10 weeks of pregnancy. On reflection this accords with previous experimental results. Pregnant women, like everybody else, lie neither on their backs nor on their sides all day. They spend about a third of their time in bed, turning from one position to another, while during the day, they stand, sit, recline, and take exercise with almost infinite variety. Clearly then, their cardiac outputs are very variable but since they spend a large portion of their time supine or sitting in postures producing some caval obstruction it can truly be said that the average cardiac output declines progressively during the third trimester. This would explain the findings in our study and the very special value of bed rest in the management of patients with left ventricular failure during the third trimester.

One possible disadvantage of such a regimen is the risk of venous thrombosis. The cases reported here were already on anticoagulants because of their prosthetic valves but otherwise heparin, administered subcutaneously as outlined by Bonnar, ${ }^{5}$ would be appropriate prophylaxis against this complication.

This research was funded by the Irish Heart Foundation and the National Maternity Hospital Research Fund.

\section{References}

1 Kerr MG. The mechanical effects of the gravid uterus in late pregnancy. Fourmal of Obstetrics and Gynaecology of the British Commonwealth 1965; 72: 513-29.

2 Lees MM, Taylor SH, Scott DB, Kerr MG. A study of cardiac output at rest throughout pregnancy. Fourmal of Obstetrics and Gynaecology of the British Commonwealth 1967; 74: 319-28.

3 Ueland K, Novy MJ, Peterson EN, Metcalfe J. Maternal cardiovascular dynamics. IV. The influence of gestational age on the maternal cardiovascular response to posture and exercise. Am 7 Obstet Gymecol 1969; 104: 656-64.

4 Mulholland HC, Boyle DMC. The effect of posture on the cardiac output during the last six weeks of pregnancy. Am Heart f 1968; 76: 291-3.

5 Bonnar J. Venous thromboembolism and pregnancy. In: Stallworthy J, Bourne G, eds. Recent advances in obstetrics and gynaecology. Edinburgh, London, New York: Churchill Livingstone, 1979:173-92.

Requests for reprints to Professor S Blake, Department of Cardiology, Mater Misericordiae Hospital, Eccles Street, Dublin 7, Ireland. 